\title{
FARMS SIZE AND EFFICIENCY OF THE PRODUCTION FACTORS IN ROMANIAN AGRICULTURE
}

\author{
Camelia Burja ${ }^{1}$, Vasile Burja ${ }^{2}$
}

\begin{abstract}
Summary
Romania has favourable conditions to develop the agriculture thanks to its significant agricultural land, climate conditions and labour force employed in this sector. In the last decades, the economic transition has determined major structural transformations within the agriculture sector, which generated certain disparities between the performance of Romania's agriculture and that of the EU's developed countries. This paper deals with the relationship between the size of agricultural holdings and the performance of the agricultural production factors in Romania. In order to achieve the paper's goal, we used the Data Envelopment Analysis and the comparative analysis, taking into account the features of the other EU countries. The research findings revealed that the efficiency of production factors used in agriculture is low and, therefore, a new organisation of holdings is required. This can lead to an optimal sizing of the holdings, so that the differences in performance compared to the EU's developed countries to be minimised or even eliminated.
\end{abstract}

Key words: farm size, production factors, efficiency, DEA

JEL: $Q 12, Q 15$

\section{Introduction}

The relationship between the farm size and efficiency plays an important role in the economic research because of its implication in the agricultural and rural development policies. The research results are contradictory. Some studies show a positive relationship (Bojnec, Latruffe, 2007), others sustain that the relationship is reversed (Verma, Bromley, 1987), and other studies show a linear relationship. The researchers' contradictory conclusions show that there are more factors influencing the farm

1 Camelia Burja, Ph.D., Full Professor, “1 Decembrie 1918” University of Alba Iulia, Faculty of Economic Science, Unirii Street no. 15-16, 510009 Alba Iulia, Romania, Phone: +40 0258806 263, E-mail: cameliaburja@yahoo.com

2 Vasile Burja, Ph.D., Full Professor, “1 Decembrie 1918” University of Alba Iulia, Faculty of Economic Science Unirii Street no. 15-16. , 510009 Alba Iulia, Romania, Phone: +40 0258 806 263,E-mail: vasileburja@yahoo.com

EP 2016 (63) 2 (361-374) 
efficiency, not only the size.

Helfand and Levine (2004) analyse the relationship between the farm size and efficiency in the Brazilian Central-West and show that there is no linear relationship between the two variables, because the farm efficiency is influenced by the type of land tenure, access to institutions and markets, use of technologies and production factors (Helfand, Levine, 2004). The nonlinear relationship between the farm size and efficiency has been also demonstrated by Hanson (2008), who shows that there is a U-shaped relationship, because it is firstly decreasing and then increasing with the farm size. The efficiency of the specialized dairy farms in Sweden depends on how the knowledge is used for the optimal combination of the production factors.

A study conducted by Latruffe et al. (2004) for a panel of individual farms in Poland, specialised in crop and livestock, shows that the livestock farms are more technically efficient than the crop farms. The results of the study show a positive relationship between the farm size and efficiency. The large farms are more efficient, while the small farms of subsistence and semi-subsistence will remain in the vicious circle of low technical efficiency in the absence of appropriate economic policies.

The reverse relationship that the small farms are more efficient was supported by the research on developing countries (Bharadwaj, 1974; Johnson, Ruttan, 1994). The explanation for this relationship is based on the assumption of intensive use of the land and the opportunity cost of labour. The small farms use the family labour, which is not remunerated.

The complexity of relationship between the farm size and efficiency is given by two variables, which in turn depend on a lot of economic and social factors, as follows: the soil type, agro-climatic conditions, the transaction costs of production factors, the technology involved, the available labour force, and so on. The cheapening of capital may lead to farm size increase, if it is complementary to the land, or to farm size decrease, if the capital can substitute the land. Of course, the disadvantages of small farms on practicing a performance management, possibilities of processing and marketing of products, introduction of technological process, etc. can be removed by providing specific agricultural services (Gordon, Davidova, 2014).

Between the levels of education of the farmers, the farm size, structure and efficiency there is a significant relationship. The individual farms generally use low-skilled workers. Also, the specialization of farms helps increase their efficiency (Mathijs, Vranken, 2000).

The Common Agricultural Policy (CAP) for the Horizon 2020 envisages the implementation of the EU 2020 Strategy to achieve a smart, sustainable and inclusive growth. The main objectives for the future CAP are: viable food production, sustainable management of natural resources and climate action, and balanced territorial development (COM, 2010). Achieving these objectives requires adjusting the size of farms to achieve maximum efficiency in terms of environmental protection and 
appropriate risk management.

The land consolidation and development of efficient agrarian structures is a global problem, whose resolution aims the food security of the population, which is in a continuous growth, and the needs of agricultural products for food are increasingly growing. Therefore, the concentration of agricultural production in farms of a certain size has been a major objective of the agricultural policy for all the countries. The role of this objective was to reduce the land fragmentation and to increase the farm size to a level that allows efficient use of the production factors.

The modernisation of agricultural structures by merging the lands is not a simple process, which started after the Second World War and is still going on. The difficulties of the process are objectives, related to the transaction costs, land market operation, but also subjective, related to the attachment to the land, the establishment and enforcement of property rights, taking risks, and so on.

Romania has the largest number of farms (agricultural holdings) of the EU. These holdings are not homogeneous. On the one hand, there are a large number of small farms, and on the other hand there are very large agricultural holdings. This structure is not characteristic to the EU developed countries, but it is specific to the Latin American countries, where the agricultural holdings are very large.

The excessive division of land and the establishment of a large number of farms in Romania have been generated by the restoration of the land ownership rights. Immediately after 1989, this aspect had a positive role, because the agriculture has played a buffer role in the labour market, absorbing a large proportion of the people laid off from other sectors of the national economy. At the same time, this phenomenon has led to a dramatic decrease in agricultural productivity, with negative impact on the supply of agricultural products to the population, the expansion of rural poverty, abandonment of agricultural land, and so on.

The EU integration has created new challenges for the farms in Romania, related to the competition with farmers from other European countries and implementation of CAP (Common Agricultural Policy). The challenges aim in particular the low competitiveness of the farms due to the inefficient use of production factors.

This research aims to analyze the relationship between the farm size and the efficient use of the production factors, as inputs. The utility of research consists of the adoption of appropriate macroeconomic and microeconomic agricultural policies, followed by effective actions to foster the development of competitive agricultural structures able to efficiently use the production factors and to generate a sustainable development of the rural areas.

For this research, we conducted comparative analysis and Data Envelopment Analysis to study the efficiency of using production factors split per size classes for assessing the Romanian farms. 
The results of research demonstrate the assumption that the large farms are more efficient in Romania, but the efficiency of using production factors split per size classes follow a U-shaped curve. The research suggests that in Romania should be created competitive agricultural structures, where the large farms have the major role, and the small farms are maintained to economic sizes able to transform them into commercial farms.

\section{Material and Methods}

This research uses the descriptive analysis of the data to present the structural disparities of agriculture in Romania compared to other countries and the Data Envelopment Analysis method (DEA) to highlight the relationship between the farm size and the efficiency of production factors in Romania. The comparator countries have an agricultural potential similar to Romania, but a higher level of agricultural development (Germany and France) and others are recently integrated into the EU (Hungary, Bulgaria and Poland).

DEA belongs to the group of the non-parametric linear programming methods and is often used to assess the productivity of decision-making units (companies, institutions, countries, and so on). The economic systems analyzed using DEA (called "decisionmaking units" - DMUs) have similar operational characteristics, but different size activities, and use different quantities of production factors. To establish the performance of using the production factors, we calculate the relative efficiency rates based on which we make the ranking of DMUs. The efficiency rates characterize the technical aspects of DMUs, based on the ratio of outputs (results) and production factors (utilised factors of production). A high technical efficiency is a condition for achieving a high economic efficiency (Ray, 2004).

The DEA method has been initially used in the variant the returns to scale are constant (CRS - proposed by Charnes, Cooper, Rhodes, 1978), and later has been developed the model variable returns to scale (VRS - developed by Banker, Charnes, Cooper, 1984). The CRS model considers $k$ decision-making units, each of them using a number of $n$ inputs and $m$ outputs.For the $k$ decision-making unit, the efficiency is calculated as follows: 


$$
E_{k}=\frac{\sum_{j=1}^{m} v_{j} y_{k j}}{\sum_{i=1}^{n} u_{i} x_{k i}}
$$

subject to:

$$
\frac{\sum_{j=1}^{m} v_{j} y_{k j}}{\sum_{i=1}^{n} u_{i} x_{k i}} \leq 1
$$

$$
\forall u_{i}, v_{i} \geq 0
$$

where: $u_{i}$ represents inputs factors weight $(x)$;

$v_{j}$ represents outputs weight $(y)$.

This system of relations can be transformed into a linear programming model that includes a set of restrictions and the minimizing objective function (input-oriented models) or maximising objective function (output-oriented models), where the unknown elements are the weights given to the inputs and outputs.

The efficiency relations can be transformed into a linear programming model that uses a set of restrictions and aims to achieve a minimum target (input-oriented models) or maximum target (output-oriented models).

In the output oriented models variant, for each $k$ decision-making unit we have:

$$
\begin{gathered}
\max \sum_{j=1}^{m} v_{j} y_{k j} \\
\text { s.t. } \quad \sum_{i=1}^{n} u_{i} x_{k i}=1 \\
\sum_{j=1}^{m} v_{j} y_{k j}-\sum_{i=1}^{n} u_{i} x_{k i} \leq 0 \\
\forall u_{i}, v_{j} \geq 0
\end{gathered}
$$


By solving the model, we find an efficiency score for all the DMUs, which place them on the efficiency frontier (score 1) or away from it (score $<1$ ). The higher the score, the better the analyzed economic system is.

The data we have used were taken from the European Union statistics (Eurostat FADN) and Romania's National Statistics. The economic size of the agricultural holdings is presented according to the FADN methodology, which is based on the Commission Regulation No 1242/2008 (EC, 2008). The regulation proposes the application of the standard output criterion for the agricultural holdings classification. It will be expressed in euro and corresponds to the sum of values obtained for each crop and livestock characteristics by multiplying the standard outputs per unit by the number of corresponding units.

\section{Results and Discussion}

Romania is a country with a significant agricultural potential in the European Union. The currently used agricultural area is 13.3 million ha, which ranks Romania on the $6^{\text {th }}$ place among the member countries of the EU, after France, Spain, Germany, UK and Poland. The agricultural potential is significant, given other features such as: quality of soil and climate conditions in Romania. According to the Agricultural Census in Romania carried out in 2010 (NIS, 2010), the largest agricultural area consists of arable land (8.3 mil ha, 62.4\%), permanent grassland and meadow (4.5 mil. ha, 33.9\%), permanent crops (0.3 mil. ha, $2.3 \%)$, and kitchen gardens ( $0.18 \mathrm{mil} \mathrm{ha,} 1.4 \%)$. The labour force employed in agriculture is oversized compared with the situation found in the other European countries.

The Romania's agricultural potential is harnessed, but with low efficiency, as can be seen in Table 1.

Table 1. Aspects of agriculture in Romania and EU in 2013

\begin{tabular}{|l|c|r|r|r|}
\hline \multicolumn{1}{|c|}{ Indicators } & U.M & \multicolumn{1}{c|}{ Romania } & EU-27 & $\begin{array}{c}\text { Romania/EU } \\
\text { \% }\end{array}$ \\
\hline Agricultural output (AO) & Mill. euro & 16260.61 & 400436.98 & 4.1 \\
\hline Net value added (NVA) & Mill. euro & 4640.56 & 103248.15 & 4.5 \\
\hline Energy, lubricants (EL) & Mill. euro & 1925.84 & 30032.99 & 6.4 \\
\hline $\begin{array}{l}\text { Fixed capital consumption } \\
\text { (FCC) }\end{array}$ & Mill. euro & 3017.51 & 61663.37 & 3.8 \\
\hline $\begin{array}{l}\text { Fertilisers and soil improvers } \\
\text { (FSI) }\end{array}$ & Mill. euro & 756.08 & 19708.35 & 2.9 \\
\hline $\begin{array}{l}\text { Plant protection products, } \\
\text { herbicides, insecticides and } \\
\text { pesticides (PHIP) }\end{array}$ & Mill. euro & 323.11 & 11299.72 & 16.1 \\
\hline $\begin{array}{l}\text { Agricultural Labour Input } \\
\text { (ALI) }\end{array}$ & 1000 AWU & 1564.0 & 9692.3 & \\
\hline
\end{tabular}




\begin{tabular}{|l|c|r|r|r|}
\hline $\begin{array}{l}\text { Utilised agricultural area } \\
\text { (UAA)(year 2012) }\end{array}$ & 1000 ha & 13733 & 176316 & 7.8 \\
\hline Number of Farms (year 2010) & 1000 holdings & 3724 & 11756 & 31.7 \\
\hline AO/UAA & Euro/ha & 1184 & 2271 & 52.1 \\
\hline AO/ALI & Euro/AWU & 10396.8 & 41314.9 & 25.2 \\
\hline
\end{tabular}

Source: Eurostat [aact_eaa01]

We see in Table 1 that Romania has about $7.8 \%$ of the utilized Agricultural area of EU, and it actually uses $1.1 \%$ of the Agricultural labour input. Also, Romania has the highest Number of farms of EU, i.e. approx. 3.7 mills. holdings (31.7\%). Nevertheless, the Agricultural output and the Net value added achieved by Romanian agriculture is only $4.1 \%$ and $4.5 \%$, respectively. The efficiency of the Utilised agricultural area and Agricultural labour input are significantly lower than the EU average (52.1\% and $25.2 \%)$.

The low efficiency of the two production factors is related to the use of capital (energy, fixed capital, plant protection, insecticides and pesticides), but also, according to our opinion, to the existence of numerous workforce used in agriculture and the large number of farms which mostly practice a subsistence agriculture. Therefore, it is required a more detailed analysis of the relationship between the production factors efficiency and the agrarian structure in Romania, i.e. the size of the farms.

A spatial analysis of the farms in Romania, compared with the developed countries (Germany and France), or with the countries which joined later the EU (Bulgaria, Hungary and Poland), shows disparities in the physical farm size and distribution (Table 2).

Table 2. Average physical farm size and distribution, 2010

\begin{tabular}{|c|c|c|c|c|c|c|}
\hline \multirow{2}{*}{ Country } & \multirow{2}{*}{$\begin{array}{c}\text { Farms, } \\
\text { No }\end{array}$} & \multirow{2}{*}{$\begin{array}{c}\text { Utilized } \\
\text { Agricultural } \\
\text { Area }\end{array}$} & \multirow{2}{*}{$\begin{array}{c}\text { Average size, } \\
\text { Ha/farm }\end{array}$} & \multicolumn{3}{|c|}{$\begin{array}{l}\% \text { of farms in different size } \\
\text { classes }\end{array}$} \\
\hline & & & & $<5$ ha & $\begin{array}{l}\geq 5 \mathrm{Ha} \\
<50 \mathrm{Ha}\end{array}$ & $\geq 50 \mathrm{Ha}$ \\
\hline EU-27 & 12014570 & 171604320 & 14.3 & $\underline{69.2}$ & 24.8 & $\underline{6.0}$ \\
\hline Bulgaria & 370490 & 4475530 & 12.1 & 91.4 & 6.4 & 2.3 \\
\hline Germany & 299130 & $\underline{16107040}$ & $\underline{53.8}$ & 9.1 & 62.4 & $\underline{28.5}$ \\
\hline France & 516100 & 27837290 & $\underline{53.9}$ & 26.9 & 35.9 & 37.2 \\
\hline Hungary & $\underline{576810}$ & 4686340 & $\underline{8.1}$ & $\underline{87.0}$ & $\underline{10.6}$ & $\underline{2.4}$ \\
\hline Poland & 1506620 & 14447290 & $\underline{9.6}$ & $\underline{55.2}$ & 43.1 & 1.8 \\
\hline Romania & 3859040 & 13306130 & 3.4 & 93.1 & 6.3 & 0.5 \\
\hline
\end{tabular}

Source: E.C., DG Agri, Rural Development in the EU Statistical and Economic Information Report 2013

We see in Table 2 that Romania has the lowest average farm size of the countries shown in Table 2, almost 4 times less than the EU-27 average. Moreover, in Romania, 93.1\% of the farms are using an area less than 5 ha. The average farm size of 3.4 ha is highly 
dispersed in Romania. On the one hand, there are 3.45 million farms (93\%) having an area of land less than 5 ha, and on the other hand 13656 farms $(0.36 \%)$ have an area of land larger than 100 ha (NIS, 2012). The causes of excessive fragmentation of land in Romania are related to the establishment of ownership of land after 1989.

In Germany, the farm average size is $53.8 \%$, and most farms (62.4\%) are using between 5 and 50 ha of agricultural land. The land structure in Germany was heavily influenced by the unification of the two countries. In Western Germany, the agriculture is carried out mostly in small-scale family farms. Before the unification, the agriculture in the Eastern Germany was organised in large-scale farms, which were maintained after the unification and adapted to the specific mechanism of market economy. There were of course huge transfers of capital from the Western Germany to the Eastern Germany's agriculture, to increase the economic performance.

In France, we notice an average size of the agricultural holdings, similar to Germany. The distribution of farms by size classes is more balanced, i.e. there are still $26.9 \%$ of farms using 5 hectares of land. The concerns about the land consolidation and reduction in the number of small farms began in France after 1950, by economic and social measures aimed to offset the incomes from the farming activities carried out by the small or elderly farmers who were leaving the land (Bullard, 2007). The land consolidation is a continuous process in France. Certain measures have been taken to improve the land management structures by building adequate infrastructure, encouraging the land exchanges, adopting appropriate legislation which sets a minimum area/farm, and so on.

Considering the number of farms, Poland is the second country in the EU. Also in this country the small farms that use less than 5 hectares are majority (55.2\%). They have a long tradition and have resisted the government attempts of collectivization in the communist era. The transition to a market economy has had a strong impact on the Polish agriculture. The small farms have absorbed much of the labour force laid off from the state farms and other sectors of the economy. But, in recent years, there has been a trend of farm consolidation in Poland, i.e. increase in the share of medium-size and large farms, but the small farms can contribute to the sustainable rural development.

The land reform, which started in Bulgaria in 1991, has created major problems such as: non-rational personification of the land ownership; the land use is characterized by a strong polarization in the size of land farms; fragmentation and dispersion of the land estates, often in different areas or settlements (Yanakieva, 2013). This situation leads to low efficiency of the agriculture in Bulgaria, difficulties in the implementation of CAP and assimilation of the EU funds.

In Hungary, the average farm size is well below the European average, because the farms with land areas less than 5 ha are numerous. In recent years, there is a process of concentration of the agricultural lands imposed by the competitiveness with the other EU countries, the implementation of CAP and adoption of the European Model of Multifunctional Agriculture to Hungary (Czimbalmos et al., 2013). 
Besides the size of the farms, there are more factors that generate performance disparities among the analysed countries. Romania uses 3.5 times less agricultural production factors in the intermediate consumption than Germany, and about 30 times less than Poland. The consumption of fixed capital is about four times lower than in Germany. Also, the fertilisers \& soil improvers and plant protection products are used in lower amounts compared to the most analysed countries, except Bulgaria (Burja, 2014). The farm size and use of production factors in agriculture generates different outputs. We can see in Figure 1 that Romania has the lowest cereal yield of the analysed countries.

The use of production factors, the size of farms and the outcomes are closely connected. But, this connection must be nuancedly interpreted, because there are many causes which determine the certain physical size of the farms. Certainly, the physical size is correlated with the economic size of the farms.

Figure 1. Cereal yield, 2004-2013, (100 kg/ha)

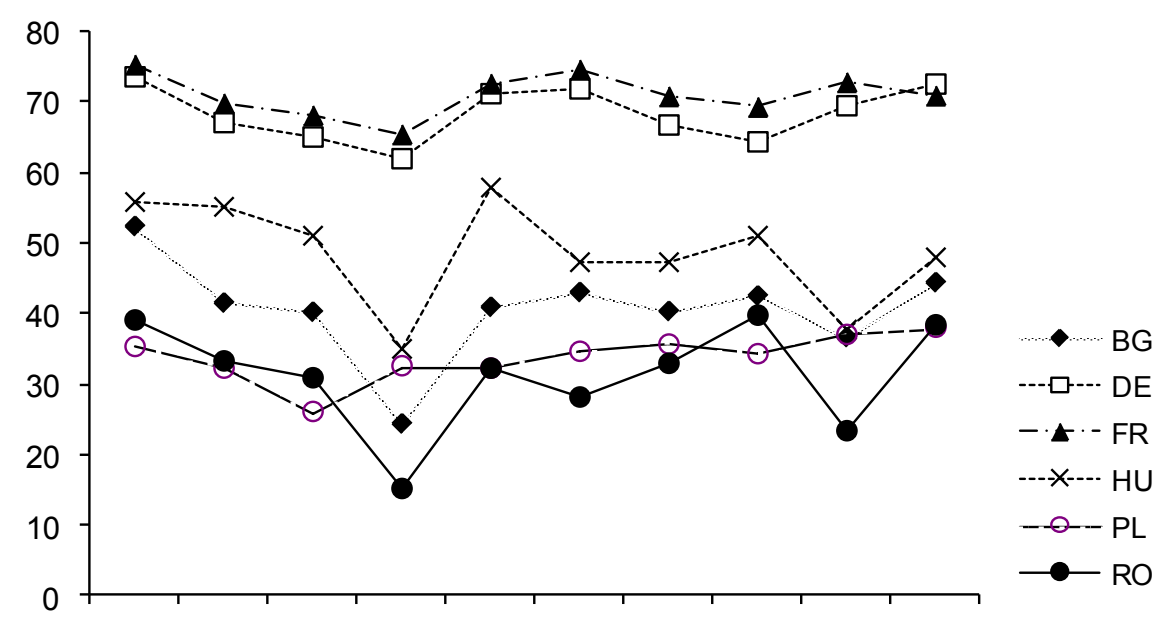

2004200520062007200820092010201120122013

Source: Eurostat, Crops products: areas and productions (apro_cpp_crop)

The FADN data enable a detailed presentation and analysis of the relationship between the farm size and the input use efficiency. Only the commercial farms are included in FADN, i.e. the farms which are large enough to provide a main activity for the farmer and a level of income sufficient to support his or her family. For the purpose of this analysis, we grouped the production factors according to the theory of classical political economy at work (Labour input), nature (Utilized agricultural area) and capital (Average farm capital). 
Table 3. The use of production factors on farm size classes in Romania (2010-2012)

\begin{tabular}{|c|l|c|r|r|r|r|}
\hline $\begin{array}{c}\text { Economic Size } \\
\text { Classes }\end{array}$ & \multicolumn{1}{|c|}{ Typology } & Symbol & \multicolumn{1}{c|}{$\begin{array}{c}\text { Total } \\
\text { output, } \\
\text { Euro }\end{array}$} & \multicolumn{1}{|c|}{$\begin{array}{c}\text { Utilized } \\
\text { Agricultural } \\
\text { Area, ha }\end{array}$} & $\begin{array}{c}\text { Labour } \\
\text { input, } \\
\text { AWU }\end{array}$ & $\begin{array}{c}\text { Average } \\
\text { farm } \\
\text { capital, } \\
\text { Euro }\end{array}$ \\
\hline $2000-<8000$ & $\begin{array}{l}\text { Very small } \\
\text { farms }\end{array}$ & VSF & 7192 & 4.41 & 1.23 & 20606 \\
\hline $8000-<25000$ & Small farms & SF & 18727 & 12.79 & 1.60 & 34768 \\
\hline $25000-<50000$ & $\begin{array}{l}\text { Medium-low } \\
\text { farms }\end{array}$ & MLF & 54602 & 51.44 & 2.44 & 95574 \\
\hline $50000-<100000$ & $\begin{array}{l}\text { Medium-large } \\
\text { farms }\end{array}$ & MHF & 105794 & 134.62 & 3.29 & 193200 \\
\hline $100000-<500000$ & Large farms & HF & 340463 & 439.25 & 6.73 & 486403 \\
\hline$>=500000$ EUR & $\begin{array}{l}\text { Very-large } \\
\text { farms }\end{array}$ & VHF & 1887337 & 1315.86 & 31.59 & 3459322 \\
\hline Total & \multicolumn{1}{|c}{-} & - & 13134 & 10.25 & 1.35 & 29841 \\
\hline
\end{tabular}

Source: Own calculations based on the FADN public database

We can see in Table 3 that the Very-large farms with an economic size of more than $€ 500,000$ are using an agricultural area of almost 300 times higher than the Very small farms. Moreover, the Labour input is about 25 times higher and, in its turn, the Average farm capital 168 times higher. According to FADN, the Average farm capital includes the Average value of the Working capital, i.e. Livestock + Permanent crops + Land improvements + Buildings + Machinery and equipment + Circulating capital.

The Very-large farms use large quantities of production factors and, naturally, they achieve higher productions, but the efficiency is generally considered as the ratio between effect and effort, i.e. the ratio between the total output and input used in the production process.

Figure 2. The relative efficiency of the production factors on farm size classes in Romania (2010-2012)

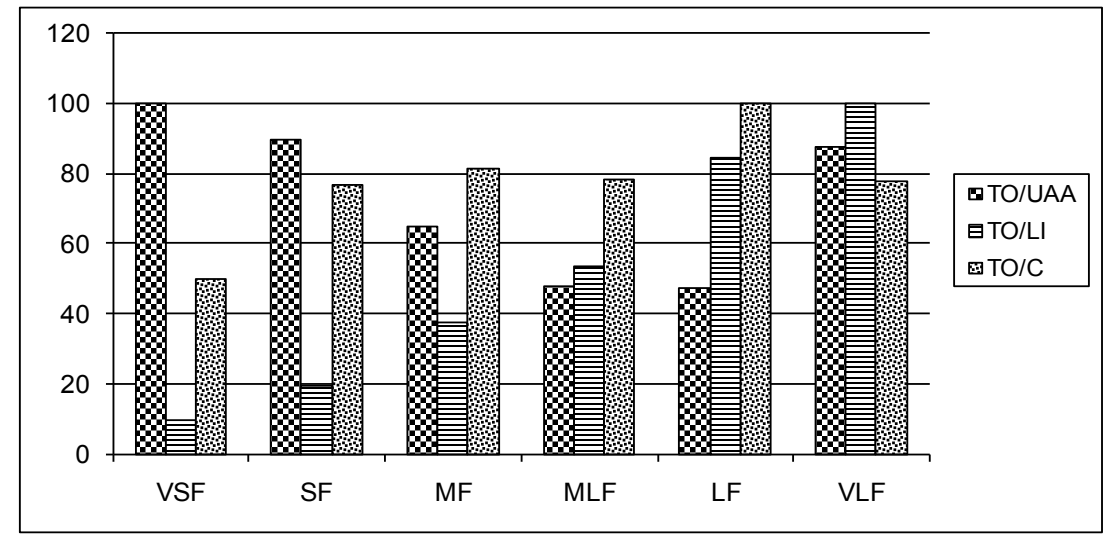

Source: Our own calculations based on the FADN public database 
We can see in Figure 2 that the Very small farms are using the agricultural area with maximum efficiency, the Large farms have maximum efficiency for the capital employed and the Very-large farms are using the Labour input with maximum efficiency. The Very-large farms are balanced in terms of relative efficiency of the production factors.

We can get an overview on the efficiency of using the production factors in the agricultural holdings in Romania, for the period taken into account, by applying the DEA method. The results are shown in Table 4.

Table 4. The efficiency of using production factors in the Romanian farms - Results from DEA

\begin{tabular}{|l|c|c|c|}
\hline \multicolumn{1}{|c|}{ Typology } & $\begin{array}{c}\text { Technical efficiency } \\
\text { CRS }\end{array}$ & $\begin{array}{c}\text { Technical efficiency } \\
\text { VRS }\end{array}$ & $\begin{array}{c}\text { Scale efficiency } \\
\text { CRS/VRS }\end{array}$ \\
\hline Very small farms & 0.964 & 1.00 & 0.964 \\
\hline Small farms & 0.950 & 0.969 & 0.980 \\
\hline Medium-low farms & 0.898 & 0.903 & 0.994 \\
\hline Medium-large farms & 0.814 & 0.869 & 0.937 \\
\hline Large farms & 0.938 & 0.941 & 0.997 \\
\hline Very-large farms & 1.00 & 1.00 & 1.000 \\
\hline Mean & 0.927 & 0.947 & 0.979 \\
\hline
\end{tabular}

Source: Our elaboration on data from FADN using DEA Software 2.1

From the data shown in the table, we note that in the constant returns to scale variant (CRS) only the Very-large farms are efficient, and in the variable returns to scale variant, the Very small farms seems to be efficient, too. The analysis results suggest a U-shaped distribution of the efficiency of using the production factors in Romania's agricultural holdings. The fact that the Very small farms appear close to the efficiency curve should not surprise, because they use the workforce efficiently and can contribute to the development of multifunctional agriculture, developed on sustainable principles (Gallutio, 2013). The Very small farms must achieve economic sizes, which transform them into commercial farms, able to exploit their relative advantages available. The large farms are of course the most efficient because of the possibilities to exploit the production factors and the obtained results, and therefore their competitiveness in the EU countries is obviousness.

\section{Conclusions}

Romania has a significant agricultural potential which would allow it to be one of the representative players on the EU market in terms of production and trade with agricultural products. However, the relatively low efficiency of the production factors used in the agricultural holdings in Romania leads to poor results compared to other EU countries that have similar agricultural potential. This is due to poor agrarian structure, but has also other causes related to the changes occurred in Romania's agriculture in the process of transition to a market economy and implementation of CAP. 
This research investigates the relationship between the size of Romanian farms and the efficiency of using the production factors. The results show that Romania has the highest number of agricultural holdings in the EU, most of which are small and practice subsistence agriculture. This agrarian structure must be improved by strengthening, for the subsistence farms to become commercial farms.

The results obtained through DEA confirm the superiority of the Very-large farms in terms of input use efficiency. The evolution of efficiency is a U-shaped curve showing that even the Very small farms can reach the efficiency frontier through an optimal combination of production factors, if operating on commercial principles.

The Small farms have an important role in the rural sustainable development through multifunctional agriculture, by ensuring the biodiversity, rural population stability, agritourism development, and so on. At the same time, the large farms provide superior efficiency when using the production factors.

The CAP objectives "Towards 2020" are pursuing viable food production, sustainable management of the natural resources \& climate action, and balanced territorial development. To achieve these objectives, a simple and certain support scheme for the small farmers will be implemented.

The direct payments will be granted only to the active farmers, and will be a real support for the better use of the production factors.

The research results suggest an approach of the agricultural development policies in Romania able to pursue the achievement of an adequate agrarian structure, leading to increased efficiency of the production factors and sustainable rural development.

\section{Literature}

1.Banker, R.D., Charnes, A., Cooper, W.W. (1984): Some Models for Estimating Technical and Scale Inefficiencies in Data Envelopment Analysis, Management science, vol. 30, no. 9, pp. 108-1092.

2.Bharadwaj, K. (1974): Production Conditions and Indian Agriculture. Cambridge University Press, Cambridge.

3.Bojnec, S., Latruffe, L. (2007): Farm size and efficiency: the case of Slovenia. 100th Jubilee Seminar of European Association of Agricultural Economists "Development of Agriculture and Rural Areas in Central and Eastern Europe”.Novi Sad, 21st-23rd June 2007.

4.Bullard, R. (2007): Land Consolidation and Rural Development, Papers în Land management, No. 10, October 2007, Anglia Ruskin University.

5.Burja V. (2014): Performance Disparities Between Agricultural Holdings Of Romania And Of The European Union, Annals - Economy Series, Constantin Brancusi University, Faculty of Economics, vol. 0, pp. 97-102, May.

6.Charnes, A, Cooper, W.W, Rhodes, E.L. (1978): Measuring the efficiency of decision 
making units, European Journal of operational Research, no. 2.

7.COM (2010) 672 final, Communication from the Commission to the European Parliament, the Council, the European Economic and Social Committee and the Committee of The Regions, The CAP towards 2020: Meeting the food, natural resources and territorial challenges of the future, Brussels, 18 November 2010, (available at: http://ec.europa.eu/agriculture/cap-post-2013/communication/ com2010-672_en.pdf).

8.Czimbalmos, R., Kovács, G., Fehér, A. (2013): Multifunctionality and farm concentration in Hungary, Research Journal of Agricultural Science, vol. 45, no. 2, pp. 52-60.

9.E.C. ,DG Agri (2013): Rural Development in the EU Statistical and Economic Information Report 2013, (available at: http://ec.europa.eu/agriculture/statistics/ rural-development/2013/full-text_en.pdf).

10. European Commission, (EC), (2008): Commission Regulation (EC) No 1242/2008 of 8 December 2008 establishing a Community typology for agricultural holdings, Official Journal of the European Union, 13.12.2008, Brussels.

11. Gallutzzo, N. (2013): Farm Dimension and Efficiency in Italian Agriculture: A Quantitative Approach, American Journal of Rural Development, vol. 1, no. 2, pp. 26-32.

12. Gorton, M, Davidova, S. (2004): Farm productivity and efficiency in the CEE applicant countries: a synthesis of results, AgricEcon, no. 30, pp. 1-16.

13. Hansson, H. (2008): Are larger farms more efficient? A farm level study of the relationships between efficiency and size on specialized dairy farms in Sweden, Agricultural and Food Science, no. 17, pp. 325-337.

14. Helfand, S. M., Levine, E. S. (2004): Farm size and the determinants of productive efficiency in the Brazilian Center-West, Agricultural Economics, vol. 31, no. 2-3, pp. 241-249.

15. Johnson, N. Ruttan, V. (1994): Why Are Farms So Small?, World Development no. 22, pp. 691-706.

16. Latruffe, L., Balcombe, K., Davidova, S., Zawalinska, K. (2004): Determinants of Technical Efficiency of Crop and Livestock Farms in Poland, Applied Economics vol. 36, no. 12, pp. 1255-1263.

17. Koester, U. (2000): The Evolving Farm Structure in East Germany, in C. Csaki and Z. Lerman, eds.,Structural Change in the Farming Sectors in Central and Eastern Europe, ECSSD Environmentally and Socially Sustainable Development, Working Paper, no. 23, Washington, DC , pp. 49-66.

18. Mathijs E., Vranken, L. (2000): Farm restructuring and efficiency in transition: Evidence from Bulgaria and Hungary, Selected Paper, American Agricultural Economics Association Annual Meeting, Tampa, Florida, July 30-August 2.

19. National Institute of Statistics (NIS), (2012): General Agricultural Census 2010, 
National results, Bucharest.

20. Ray, S.C. (2004): Data Envelopment Analysis Theory an Techniques for Economics and Operations Research, Cambridge University Press, UK.

21. Szumelda, A. (2013): Is Small Beautiful? The Debate on the Future of Small Individual Farms in Poland, Eastern European Countryside, vol 19.

22. Verma, B., Bromley, D. (1987): The political economy of farm size in India: The elusive quest, Economic Development of Cultural Change, vol. 35, no. 4, pp. 791808.

23. Yanakieva, I. (2007): The agricultural land problems in Bulgaria and implementation of the Common Agricultural Policy, Agricultural Economics, no. 53, pp. 189-193. 